\title{
Reel and sheet cutting at a paper mill ${ }^{\text {is }}$
}

\author{
M. Helena Correia ${ }^{\mathrm{a}, \mathrm{b}, *}$, José F. Oliveira ${ }^{\mathrm{a}, \mathrm{c}}$, J. Soeiro Ferreira ${ }^{\mathrm{a}, \mathrm{c}}$ \\ ${ }^{a}$ INESC Porto, Instituto de Engenharia de Sistemas e Computadores do Porto, 4200-465 Porto, Portugal \\ ${ }^{\mathrm{b}}$ Faculdade de Economia e Gestao, Universidade Católica Portuguesa, 4169-005 Porto, Portugal \\ ${ }^{\mathrm{c}}$ Faculdade de Engenharia, Universidade do Porto, 4200-465 Porto, Portugal
}

Keywords: Combinatorial optimization; Cutting-stock; Heuristics

\begin{abstract}
This work describes a real-world industrial problem of production planning and cutting optimization of reels and sheets, occurring at a Portuguese paper mill. It will focus on a particular module of the global problem, which is concerned with the determination of the width combinations of the items involved in the planning process: the main goal consists in satisfying an order set of reels and sheets that must be cut from master reels. The width combination process will determine the quantity/weight of the master reels to be produced and their cutting patterns, in order to minimize waste, while satisfying production orders.

A two-phase approach has been devised, naturally dependent on the technological process involved. Details of the models and solution methods are presented. Moreover some illustrative computational results are included.
\end{abstract}

\section{Introduction}

Planning the paper production at a paper mill assumes several essentially distinct forms, each of which has its own particular characteristics, requiring different mathematical formulation and solution methods [1-3]. However, trim loss minimization is usually a component of the objective function. Other components take account of factors such as setup, processing time, number and characteristics

\footnotetext{
Partially supported by FCT, POSI and FEDER (POSI/SRI/40908/2001), PRAXIS XXI/2/2.1/TPAR/2046/95 and PRAXIS XXI/BD/4324/96.

${ }^{*}$ Corresponding author. INESC Porto, Instituto de Engenharia de Sistemas e Computadores do Porto, 4200-465 Porto, Portugal.

E-mail addresses: mcorreia@inescporto.pt (M.H. Correia), jfo@fe.up.pt (J.F. Oliveira), jsoeiro@inescporto.pt (J.S. Ferreira).
} 
of cutting patterns. Additionally, there are usually several constraints involved, concerning customers specifications, strategic decisions and technological characteristics of the production process.

This paper describes a system developed by request of a Portuguese paper mill, Companhia de Papel do Prado (CPP), to support its production planning, focusing on the production and cutting of paper reels. This work is part of a broader system, named COOL (COOL stands for the Portuguese words meaning optimized combination of widths), which is intended to support the implementation of an optimizing policy for paper production and stock management.

The problem tackled in this paper concerns the definition of cutting patterns and quantity of paper to produce in order to satisfy a set of ordered reels and sheets, grouped by type of paper and grade. It basically deals with the problem of planning the paper production and cutting of the master reels in order to satisfy a set of orders. The cutting plans to associate to the master reels must be defined considering minimization of waste while satisfying the ordered quantities. A variety of technological and operational constraints are involved in the planning process, causing an interesting and difficult trim problem.

From this perspective, this problem can be included in the broad family of Cutting-Stock Problems [4-6]. The problem formulation adopted disregards trim loss at the end of the reels (as it was considered irrelevant when compared with that occurring at the edges of the paper reels, which runs all along the paper length) and so, a 1D approach has been devised. The need of a two-phase methodology was determined by the technological characteristics of the cutting process. Other 1D two-phase cutting-stock problems can be found in published literature. Besides paper industry, similar approaches are also applied in other industries, such as the steel industry $[7,8]$ and the plastic film industry [9].

We propose an original solution method for the problem described above, which leads to considerable improvements in terms of paper savings when compared with those solutions obtained manually, as confirmed by the paper mill. The procedure developed is based on two distinct linear programming models, which are solved by a Simplex algorithm. Then, the solutions obtained are rounded in a post-optimization procedure, in order to satisfy integer constraints previously ignored. The quality of the solutions obtained are also validated by the resolution of an integer programming model of the problem, solved using the commercial optimization software CPLEX v.6.0.

The paper is organized as follows. Section 2 introduces the production problem and its industrial background. Particular emphasis will be given to those features of the industrial environment, which were relevant for the solution approach developed. Sections 3 and 4 will describe the problem and the methodology developed to solve it, respectively. A small example is considered throughout Section 4 in order to illustrate the solution procedure. In Section 5 some results will be presented and discussed.

\section{Industrial environment}

This case study takes place at a Portuguese paper mill, which can be considered as a vertical industry, since it produces paper products from pulp. The products are supplied both in reels and sheets. This industry operates in two types of markets: one in which the paper products have standard dimensions and other where paper products have make-to-order dimensions. The production cycle 


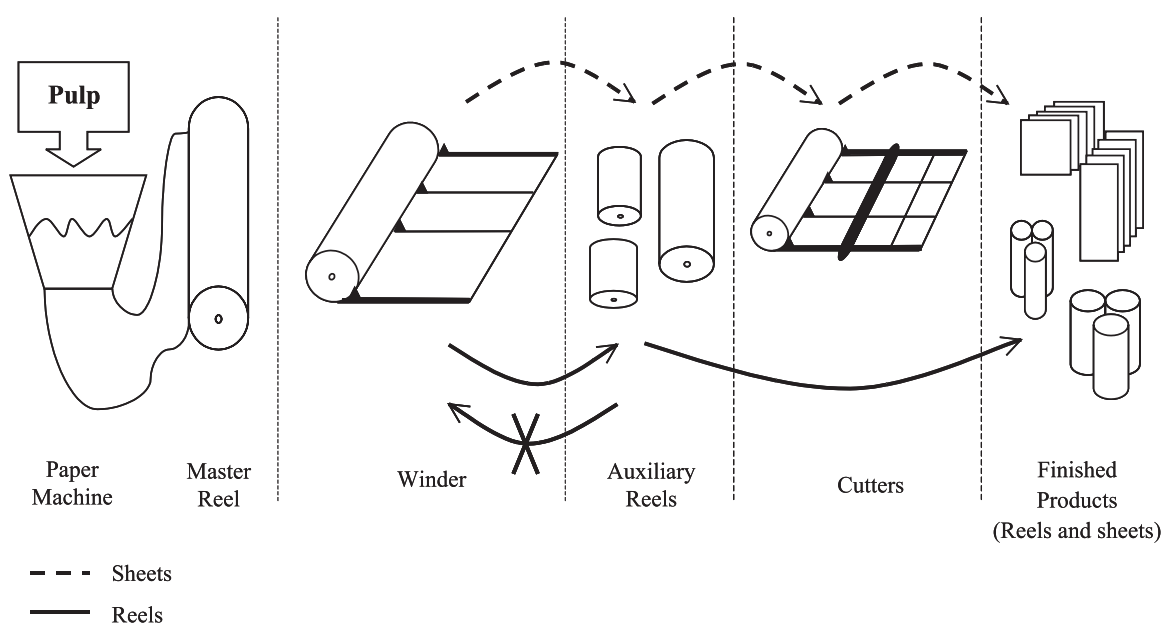

Fig. 1. Production flow.

is of 6 weeks and, for technological reasons, there is a pre-defined production sequence in which paper is produced in ascending or descending grades.

Fig. 1 shows the production flow of the paper products through out the production line. The paper is produced at the paper machine from pulp and is wound into a master reel of fixed width. Then, the master reel follows to the winder where it is cut into smaller reels. These reels either go straight to the customer or to the Intermediate Stock, or are cut into sheets at the cutters. These cut-to-size sheets either go to the customer or to the Standard Stock.

Both at the winder and cutters there is a small shred of fixed width cut-off all along the paper length. This scrap has been quite determinant for the solution process adopted.

Fig. 2 illustrates the relative perspectives of planning and production processes, emphasizing the products and sub-products involved. Planning and Production follow opposite directions. Planning is based on the customers specifications of ordered products. Ordered reels and sheets of the same type of paper and grade, and belonging to the same Production Order, are combined into auxiliary reels. These auxiliary reels may include either reels or sheets, but never both. So, two types of auxiliary reels will be distinguished: auxiliary reels of sheets and auxiliary reels of reels. Auxiliary reels are then combined into cutting patterns that are associated to master reels.

The concept of auxiliary reel has been introduced for a better understanding of both the production procedure and the solution approach adopted. It is strictly related to the technological process involved, which requires the consideration of additional scrap width whenever the cutters are used. The definition of sub-patterns inside the main cutting patterns to be cut from the master reels has determined the two-phase solution approach considered.

There is a set of constraints that must be considered in the generation of the auxiliary reels and cutting patterns and which will be described later in Section 3. These constraints determine pattern feasibility.

The order system is schematised in Fig. 3. An order can be placed by the national market or by the international market (as this company also operates outside Portugal) and is processed by the Marketing Department. The Marketing Department can also generate an internal order, similar to the 


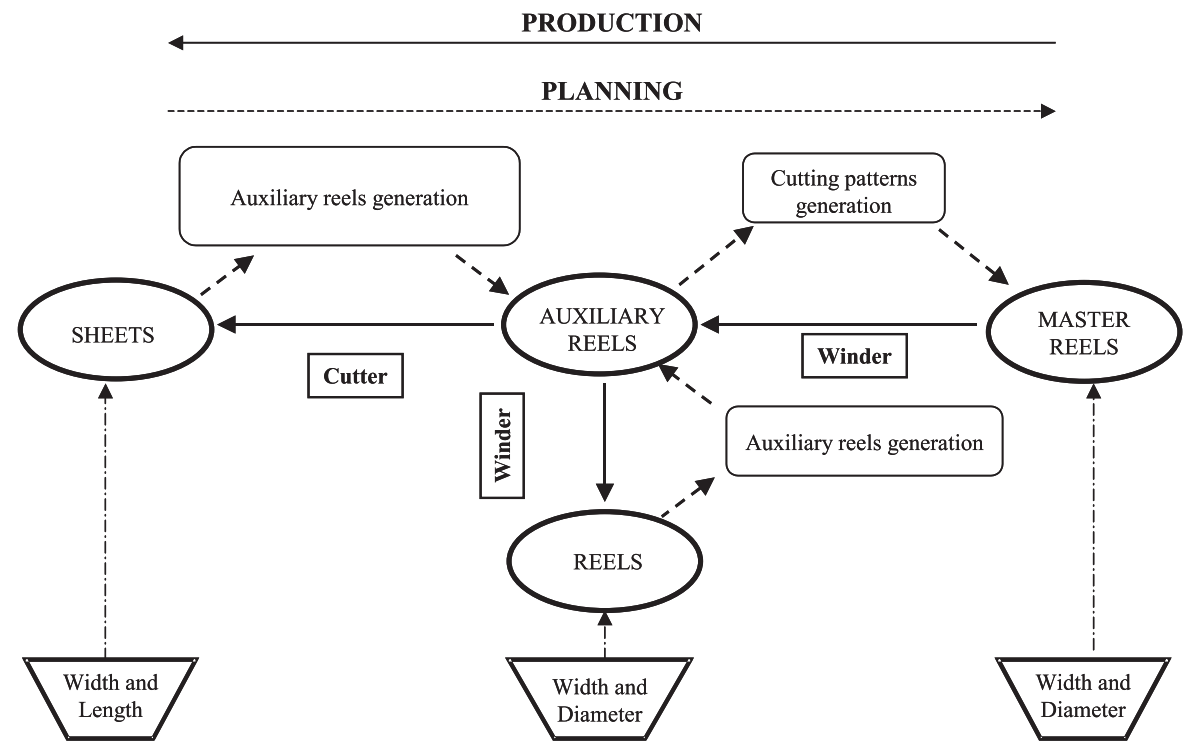

Fig. 2. Planning and production processes.
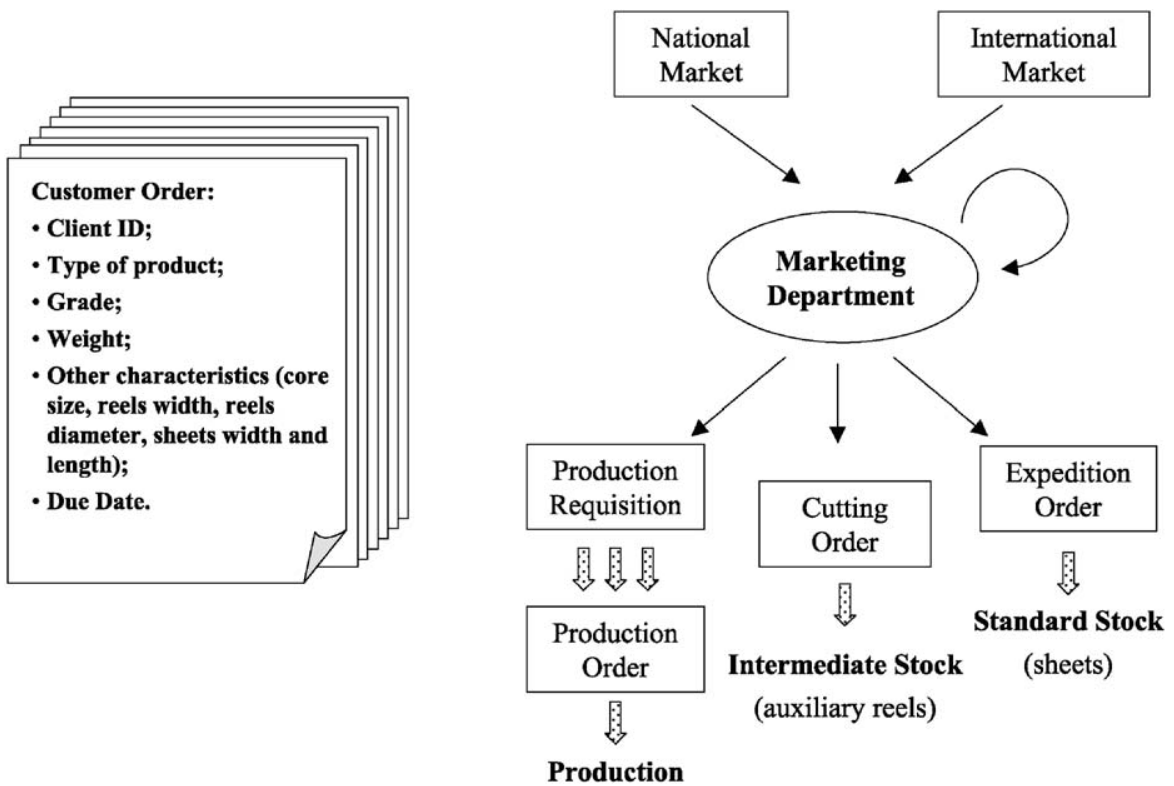

Fig. 3. Order system.

external orders, if it is considered appropriated. These orders can originate a Production Requisition, a Cutting Order or an Expedition Order. A Production Requisition is grouped with other existing Production Requisitions of the same type of paper and grade, resulting in a Production Order, which then follows to production. A Cutting Order occurs when a customer order of reels can be satisfied by 
existing reels (stocked at the Intermediate Stock) and an Expedition Order occurs when a customer order of sheets can be satisfied by existing sheets (stocked at the Standard Stock).

\section{Problem description}

The work presented in this paper is mainly concerned with the cutting patterns generation process, which will determine the quantity/weight of the master reels to produce and the associated cutting patterns, in order to minimize waste while satisfying a production order. The system developed will support the cutting planning of a Production Order, not interfering with decisions related to the orders to satisfy and the type of paper to produce in each production cycle. These are previous decisions made by the Marketing Department, eventually supported by a simulation using the system COOL.

Some constraints must be considered during the definition of the cutting patterns to associate to a master reel. These constraints can be grouped in two sub-sets:

- Operational constraints (imposed by management and customers specifications):

- Only reels of identical weight per width unit (reels with the same length of paper) can be combined.

- Only reels of identical internal and external diameters can be combined.

- Customer specifications of internal and external diameters must be satisfied.

- Assignment of the auxiliary reels to the cutters must be considered, since cutters have different characteristics.

- Minimum width is imposed to cutting patterns, in order to optimize the use of the machinery available.

- Technological constraints (mainly due to machinery characteristics):

- Maximum and minimum widths of the master reel at the winder (input).

- Limited number of winder slitting knives.

- Maximum and minimum sheet lengths at the cutters.

- Maximum and minimum sheet widths at the cutters.

- Limited number of slitting knives at the cutters.

- Maximum diameter of input reels at the cutters.

$\circ$ Edge trim loss both at the winder and cutters.

There are European Standard Tolerances in use at the paper industry, which must be taken into account when fulfilling an order (see Table 1). The client is obliged to accept deviations of the quantity ordered in these ranges. When over-production above maximum tolerances occurs, the Marketing Department can try to negotiate the acceptance of this extra quantity with the client. Due to losses inherent to production, negative tolerances (under-production) are never considered during the planning phase.

\section{Solution procedure}

The solution procedure adopted is clearly influenced by the production flow. It is divided into three main stages, which are represented in Fig. 4. The first stage consists in enumerating all the 
Table 1

European standard tolerances in the paper industry

\begin{tabular}{lc}
\hline Quantity ordered & Tolerance \\
\hline Above 100 tons (included) & Previous agreement \\
$50-100$ tons (included) & $+/-4 \%$ \\
$20-50$ tons (included) & $+/-6 \%$ \\
$10-20$ tons (included) & $+/-8 \%$ \\
$5-10$ tons (included) & $+/-10 \%$ \\
$3-5$ tons (included) & $+/-15 \%$ \\
Less than 3 tons (included) & $+/-20 \%$ \\
\hline
\end{tabular}

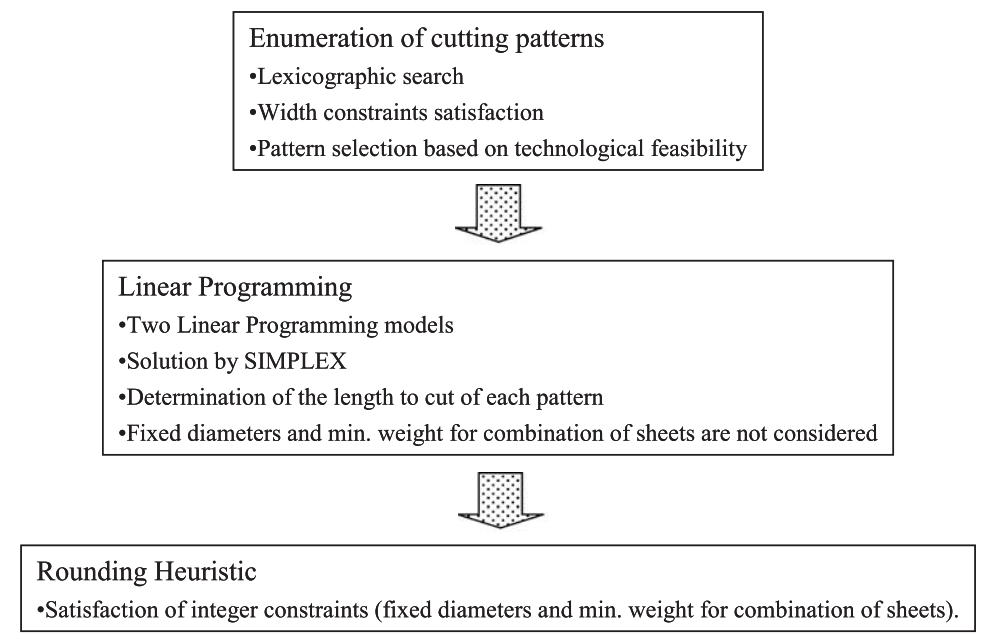

Fig. 4. Three stages of the solution procedure.

auxiliary reels and cutting patterns, based on a fixed width for the master reel and on the widths of the ordered items. The resultant set of cutting patterns is then submitted to a selection process through which undesirable auxiliary reels/cutting patterns are eliminated. All the remaining cutting patterns must be feasible in terms of the technological and operational constraints imposed to the production process.

In the second stage, the cutting patterns generated and accepted during the first stage are used as columns in a linear programming model of the optimization problem. Two linear programming models were developed. These models are solved by a Simplex algorithm [10].

Finally, to attain feasible solutions to the real problem, the linear programming solutions are submitted to a rounding procedure, which is intended to satisfy those constraints that involve integer or binary variables and that were ignored in the previous stage.

In the following sections each one of these stages will be presented in detail.

A small real industrial example is introduced to illustrate the solution procedure and will be followed through out its description. It concerns the production planning of paper in master reels 
Table 2

Data of a small example

\begin{tabular}{llllll}
\hline Production requisition & $\begin{array}{l}\text { Width } \\
(\mathrm{mm})\end{array}$ & $\begin{array}{l}\text { Length }^{\mathrm{a}} \\
(\mathrm{mm})\end{array}$ & $\begin{array}{l}\text { Weight } \\
(\mathrm{kg})\end{array}$ & $\begin{array}{l}\text { Ext. diam. } \\
(\mathrm{mm})\end{array}$ & $\begin{array}{l}\text { Int. diam. }^{\mathrm{b}} \\
(\mathrm{mm})\end{array}$ \\
\hline PR 1001 & 900 & 980 & 12,000 & - & - \\
PR 1002 & 750 & 600 & 9000 & 1600 & 120 \\
PR 1003 & 800 & - & 10,000 & 1500 & 150 \\
PR 1004 & 650 & - & 2300 & - \\
\hline
\end{tabular}

${ }^{\mathrm{a}}$ When the production requisition refers to a reel the length is not specified.

${ }^{\mathrm{b}}$ External/internal diameter not specified means that either it refers to a sheet order or, in the case of a reel order, these values where not specified by the customer.

of $2520 \mathrm{~mm}$ width. The paper grade is $250 \mathrm{~g} / \mathrm{m}^{2}$ and its thickness is $345 \mu \mathrm{m}$. The Production Requisitions involved are described in Table 2.

\section{Pattern enumeration}

The need to consider a fixed width of scrap along the paper length at the cutters, prevented the use of traditional 1D cutting-stock techniques to solve this problem. That is why a two-phase methodology has been adopted. First, the reels and sheets are grouped into auxiliary reels (of reels and sheets, separately). Then, the auxiliary reels are joined to build the cutting patterns, which are associated to a master reel of fixed width. The enumeration process, both of the auxiliary reels and of the cutting patterns, is based in a lexicographic search.

Auxiliary reels of reels are obtained by combining the widths of the different types of ordered reels:

$$
\begin{aligned}
& W A R_{a_{r}}=\sum_{i=1}^{n_{i}} A_{a_{r} i} W R_{i}+S w \quad a_{r}=1, \ldots, n_{a_{r}}, \\
& \sum_{i=1}^{n_{i}} A_{a_{r} i} \geqslant 1 \quad a_{r}=1, \ldots, n_{a_{r}},
\end{aligned}
$$

where $W A R_{a_{r}}$ is the width of the auxiliary reel of reels $a_{r}, n_{a_{r}}$ the total number of auxiliary reels of reels, $A_{a_{r} i}$ the No. of reels of type $i$ in the auxiliary reel of reels $a_{r}, W R_{i}$ the Width of reel of type $i, n_{i}$ the No. of reel types, and $S w$ the edge trim loss at the winder.

Feedback of auxiliary reels of reels at the winder is not allowed (Fig. 1) at the company, and so, when building the auxiliary reels of reels, $S w$ equals $0, A_{a_{r} i}$ must always be considered 0 or 1 and

$$
\sum_{i=1}^{n_{i}} A_{a_{r} i}=1 \quad a_{r}=1, \ldots, n_{a_{r}} .
$$

In the small example considered, there are only two auxiliary reels of reels, corresponding to each type of ordered reels (see Table 3 ). 
Table 3

Auxiliary reels of reels.

\begin{tabular}{llr}
\hline $\begin{array}{l}\text { Auxiliary reel } \\
\text { of reels }\end{array}$ & $\begin{array}{l}\text { Width } \\
(\mathrm{mm})\end{array}$ & Cutting pattern \\
\hline ARR 1 & 800 & $1 \times 800(\mathrm{PR} 1003)$ \\
ARR 2 & 650 & $1 \times 650(\mathrm{PR} 1004)$ \\
\hline
\end{tabular}

Table 4

Auxiliary reels of sheets

\begin{tabular}{|c|c|c|}
\hline $\begin{array}{l}\text { Auxiliary reel } \\
\text { of sheets }\end{array}$ & $\begin{array}{l}\text { Width } \\
(\mathrm{mm})\end{array}$ & Cutting pattern \\
\hline ARS 1 & 765 & $1 \times 750(\mathrm{PR} 1002)$ \\
\hline ARS 2 & 915 & $1 \times 900(\mathrm{PR} 1001)$ \\
\hline ARS 3 & 1515 & $2 \times 750(\mathrm{PR} 1002)$ \\
\hline ARS 4 & 1815 & $2 \times 900(\mathrm{PR} 1001)$ \\
\hline $\operatorname{ARS} 5^{\mathrm{a}}$ & 1665 & $1 \times 750(\mathrm{PR} \mathrm{1002)}+1 \times 900(\mathrm{PR} 1001)$ \\
\hline ARS $6^{\mathrm{b}}$ & 2265 & $3 \times 750(\mathrm{PR} 1002)$ \\
\hline ARS $7^{\mathrm{b}}$ & 2415 & $2 \times 750(\mathrm{PR} \mathrm{1002)}+1 \times 900(\mathrm{PR} 1001)$ \\
\hline
\end{tabular}

${ }^{\text {a }}$ Rejected because it includes orders of different lengths.

${ }^{b}$ Rejected because it exceeds maximum number of sheets at the cutter ( 2 sheets).

Auxiliary reels of sheets are obtained by combining the widths of the different types of ordered sheets:

$$
\begin{aligned}
& W A S_{a_{s}}=\sum_{j=1}^{n_{j}} E_{a_{s} j} W S_{j}+S c \quad a_{s}=1, \ldots, n_{a_{s}}, \\
& \sum_{j=1}^{n_{j}} E_{a_{s} j} \geqslant 1 \quad a_{s}=1, \ldots, n_{a_{s}},
\end{aligned}
$$

where $W A S_{a_{s}}$ is the width of the auxiliary reel of sheets $a_{s}, n_{a_{s}}$ the total number of auxiliary reels of sheets, $E_{a_{s} j}$ the No. of sheets of type $j$ in the auxiliary reel of sheets $a_{s}, W S_{j}$ the width of sheet type $j, n_{j}$ the No. of sheet types, and $S c$ the edge trim loss at the cutter.

The auxiliary reels must be tested in order to eliminate those which do not satisfy technological and operational constraints imposed to the cutting process, such as: maximum and minimum width of input reels at the cutters, number of slitting knives at the cutters, an auxiliary reel of sheets must include only ordered sheets of the same length, etc. (see Section 3). Those auxiliary reels which do not satisfy this constraints will not be considered in the next phase of patterns generation.

For the example previously introduced in Tables 2, 7 auxiliary reels of sheets were generated. The cutting patterns of these auxiliary reels are described in Table 4 . The width of these auxiliary reels includes the fixed width of the edge trim loss at the cutter $(15 \mathrm{~mm})$. The three auxiliary reels marked were eliminated as they do not entirely satisfy the technological and operational constraints. 
Then, the remaining auxiliary reels of sheets and reels are combined into cutting patterns, which are associated to the master reels:

$$
\begin{aligned}
& C P_{p}=\sum_{a_{r}=1}^{n_{a_{r}}} N_{p a_{r}} \cdot W A R_{a_{r}}+\sum_{a_{s}=1}^{n_{a_{s}}} N_{p a_{s}} \cdot W A S_{a_{s}} \quad p=1, \ldots, n_{p}, \\
& \sum_{a_{r}=1}^{n_{a_{r}}} N_{p a_{r}}+\sum_{a_{s}=1}^{n_{a_{s}}} N_{p a_{s}} \geqslant 1 \quad p=1, \ldots, n_{p},
\end{aligned}
$$

where $C P_{p}$ is the width of cutting pattern $p, n_{p}$ the total number of cutting patterns, $N_{p a_{r}}$ the No. of auxiliary reels of reels $a_{r}$ in the cutting pattern $p$, and $N_{p a_{s}}$ the No. of auxiliary reels of sheets $a_{s}$ in the cutting pattern $p$.

Next, the resulting cutting patterns are also submitted to evaluation in order to eliminate those patterns that do not satisfy the imposed technological and operational constraints which determine patterns feasibility: maximum and minimum width of input reels at the winder, limited number of slitting knives at the winder, same length of paper of all the auxiliary reels, etc. (see Section 3 ). The remaining cutting patterns must satisfy those width constraints imposed to the process of producing and cutting the master reels.

For the previously considered example, 37 patterns were first generated. These cutting patterns are described in Table 5. Then, these cutting patterns were submitted to the process of selectionelimination of those which are infeasible, concerning the technological and operational constraints imposed to the cutting of the master reels, and 17 of the former 37 cutting patterns were eliminated. The reasons for the rejection of each cutting pattern are stated in Table 6 .

Table 7 describes some real industrial instances, in terms of the number of feasible cutting patterns obtained through the enumeration process. The percentages on the second and third column refer to the relative dimension of the average width of the small items (reels or sheets) and the width of the master reel. It can be observed that the final number of cutting patterns is quite variable. This variation is due not only to the number of ordered items but also to their relative dimensions when compared to the master reel.

Finally, after guaranteeing the feasibility of the cutting patterns, it is necessary to determine the quantities to produce/associate to each master reel while satisfying a set of constraints imposed on paper length. This will be considered on the next stage.

\section{Linear programming models}

At this second stage of the solution procedure, two linear programming (LP) models were developed and implemented, in order to evaluate which one meets better the company goals. Note that these LP models are not any relaxation of integer programming (IP) models of the problem. In fact, they simply ignore those constraints which would involve integer or binary variables. These constraints are mainly imposed on the length of the paper and will only be considered in the post-optimization procedure described in Section 4.3.

These two LP models essentially differ in the way they deal with overproduction: Model(1) allows production to the Intermediate Stock while trying to keep production quantities within standard tolerances; Model(2) does not produce to the Intermediate Stock but tries to explore the possibility 
Table 5

Cutting patterns before the selection-elimination process

\begin{tabular}{|c|c|c|}
\hline $\begin{array}{l}\text { Final } \\
\text { pattern }\end{array}$ & $\begin{array}{l}\text { Width } \\
(\mathrm{mm})\end{array}$ & Cutting pattern \\
\hline FP 1 & 650 & $1 \times 650(\mathrm{ARR} 2)$ \\
\hline FP 2 & 765 & $1 \times 765($ ARS 1$)$ \\
\hline FP 3 & 800 & $1 \times 800($ ARR 1$)$ \\
\hline FP 4 & 915 & $1 \times 915($ ARS 2) \\
\hline FP 5 & 1515 & $1 \times 1515($ ARS 3) \\
\hline FP 6 & 1815 & $1 \times 1815($ ARS 4) \\
\hline FP 7 & 1300 & $2 \times 650(\mathrm{ARR} 2)$ \\
\hline FP 8 & 1415 & $1 \times 650(\operatorname{ARR} 2)+1 \times 765($ ARS 1$)$ \\
\hline FP 9 & 1450 & $1 \times 650(\operatorname{ARR} 2)+1 \times 800($ ARR 1$)$ \\
\hline FP 10 & 1565 & $1 \times 650($ ARR 2$)+1 \times 915($ ARS 2$)$ \\
\hline FP 11 & 2165 & $1 \times 650($ ARR 2$)+1 \times 1515($ ARS 3$)$ \\
\hline FP 12 & 2465 & $1 \times 650(\operatorname{ARR} 2)+1 \times 1815(\operatorname{ARS} 4)$ \\
\hline FP 13 & 1530 & $2 \times 765($ ARS 1$)$ \\
\hline FP 14 & 1565 & $1 \times 765($ ARS 1$)+1 \times 800($ ARR 1$)$ \\
\hline FP 15 & 1680 & $1 \times 765($ ARS 1$)+1 \times 915($ ARS 2$)$ \\
\hline FP 16 & 2280 & $1 \times 765($ ARS 1$)+1 \times 1515($ ARS 3$)$ \\
\hline FP 17 & 1600 & $2 \times 800(\mathrm{ARR} 1)$ \\
\hline FP 18 & 1715 & $1 \times 800($ ARR 1$)+1 \times 915($ ARS 2$)$ \\
\hline FP 19 & 2315 & $1 \times 800($ ARR 1$)+1 \times 1515($ ARS 3$)$ \\
\hline FP 20 & 1830 & $2 \times 915($ ARS 2) \\
\hline FP 21 & 2430 & $1 \times 915($ ARS 2$)+1 \times 1515($ ARS 3$)$ \\
\hline FP 22 & 1950 & $3 \times 650(\mathrm{ARR} 2)$ \\
\hline FP 23 & 2065 & $2 \times 650($ ARR 2$)+1 \times 765($ ARS 1$)$ \\
\hline FP 24 & 2100 & $2 \times 650($ ARR 2$)+1 \times 800($ ARR 1$)$ \\
\hline FP 25 & 2215 & $2 \times 650($ ARR 2$)+1 \times 915($ ARS 2$)$ \\
\hline FP 26 & 2180 & $1 \times 650($ ARR 2$)+2 \times 765($ ARS 1$)$ \\
\hline FP 27 & 2215 & $\begin{aligned} 1 \times 650(\text { ARR } 2) & +1 \times 765(\text { ARS } 1) \\
& +1 \times 800(\text { ARR } 1)\end{aligned}$ \\
\hline FP 28 & 2330 & $\begin{aligned} 1 \times 650(\text { ARR } 2) & +1 \times 765(\text { ARS } 1) \\
& +1 \times 915(\text { ARS } 2)\end{aligned}$ \\
\hline FP 29 & 2250 & $1 \times 650($ ARR 2$)+2 \times 800($ ARR 1$)$ \\
\hline FP 30 & 2365 & $\begin{aligned} 1 \times 650(\text { ARR } 2) & +1 \times 800(\text { ARR } 1) \\
& +1 \times 915(\text { ARS } 2)\end{aligned}$ \\
\hline FP 31 & 2480 & $1 \times 650($ ARR 2$)+2 \times 915($ ARS 2$)$ \\
\hline FP 32 & 2295 & $3 \times 765($ ARS 1$)$ \\
\hline FP 33 & 2330 & $2 \times 765($ ARS 1$)+1 \times 800($ ARR 1$)$ \\
\hline FP 34 & 2445 & $2 \times 765($ ARS 1$)+1 \times 915($ ARS 2$)$ \\
\hline FP 35 & 2365 & $1 \times 765($ ARS 1$)+2 \times 800($ ARR 1) \\
\hline FP 36 & 2480 & $\begin{aligned} 1 \times 765(\text { ARS } 1) & +1 \times 800(\text { ARR } 1) \\
& +1 \times 915(\text { ARS } 2)\end{aligned}$ \\
\hline FP 37 & 2400 & $3 \times 800(\mathrm{ARR} 1)$ \\
\hline
\end{tabular}


Table 6

Cutting patterns eliminated during the selection-elimination process

\begin{tabular}{|c|c|c|}
\hline $\begin{array}{l}\text { Final } \\
\text { pattern }\end{array}$ & $\begin{array}{l}\text { Width } \\
(\mathrm{mm})\end{array}$ & Cutting pattern \\
\hline FP $9^{\mathrm{a}}$ & 1450 & $1 \times 650(\operatorname{ARR} 2)+1 \times 800($ ARR 1$)$ \\
\hline FP $13^{\mathrm{b}}$ & 1530 & $2 \times 765($ ARS 1$)$ \\
\hline FP $14^{\mathrm{c}}$ & 1565 & $1 \times 765(\mathrm{ARS} 1)+1 \times 800(\mathrm{ARR} 1)$ \\
\hline FP $18^{\mathrm{c}}$ & 1715 & $1 \times 800(\mathrm{ARR} 1)+1 \times 915(\mathrm{ARS} 2)$ \\
\hline FP $19^{c}$ & 2315 & $1 \times 800($ ARR 1$)+1 \times 1515($ ARS 3$)$ \\
\hline FP $20^{\mathrm{b}}$ & 1830 & $2 \times 915($ ARS 2$)$ \\
\hline FP $24^{\mathrm{a}}$ & 2100 & $2 \times 650($ ARR 2$)+1 \times 800($ ARR 1$)$ \\
\hline FP $26^{\mathrm{b}}$ & 2180 & $1 \times 650(\operatorname{ARR} 2)+2 \times 765(\operatorname{ARS} 1)$ \\
\hline FP $27^{a}$ & 2215 & $\begin{aligned} 1 \times 650(\operatorname{ARR} 2) & +1 \times 765(\text { ARS } 1) \\
& +1 \times 800(\text { ARR } 1)\end{aligned}$ \\
\hline FP $29^{a}$ & 2250 & $1 \times 650(\operatorname{ARR} 2)+2 \times 800($ ARR 1$)$ \\
\hline FP $30^{\mathrm{a}}$ & 2365 & $\begin{aligned} 1 \times 650(\operatorname{ARR} 2) & +1 \times 800(\text { ARR } 1) \\
& +1 \times 915(\text { ARS } 2)\end{aligned}$ \\
\hline FP $31^{\mathrm{b}}$ & 2480 & $1 \times 650(\operatorname{ARR} 2)+2 \times 915(\operatorname{ARS} 2)$ \\
\hline FP $32^{\mathrm{b}}$ & 2295 & $3 \times 765($ ARS 1$)$ \\
\hline FP $33^{\mathrm{b}}$ & 2330 & $2 \times 765($ ARS 1$)+1 \times 800($ ARR 1$)$ \\
\hline FP $34^{\mathrm{b}}$ & 2445 & $2 \times 765(\operatorname{ARS} 1)+1 \times 915(\operatorname{ARS} 2)$ \\
\hline $\mathrm{FP} 35^{\mathrm{c}}$ & 2365 & $1 \times 765($ ARS 1$)+2 \times 800($ ARR 1$)$ \\
\hline $\mathrm{FP} 36^{\mathrm{c}}$ & 2480 & $\begin{aligned} 1 \times 765(\text { ARS } 1) & +1 \times 800(\text { ARR } 1) \\
& +1 \times 915(\text { ARS } 2)\end{aligned}$ \\
\hline
\end{tabular}

${ }^{a}$ Auxiliar reels ARR 1 (PR 1003) and ARR 2 (PR 1004) have different associated lengths and must be wound into different internal diameters.

${ }^{b}$ There are smaller patterns with the same composition in terms of Production Requisitions, but with less scrap.

${ }^{\mathrm{c}}$ The cutter does not support an input reel wound into an internal diameter of $120 \mathrm{~mm}$ (which is the internal diameter of ARR 1 (PR 1003)).

of negotiating quantities beyond tolerances with the customer. Both models consider a master reel of fixed width and of infinite length, meaning that no discontinuities in master reels are tackled.

The first LP model, Model(1), minimizes the total length of paper produced, being the length of paper to cut with each pattern, $x_{p}$, the decision variables of the model:

$$
\min Z=\sum_{p=1}^{n_{p}} x_{p} .
$$

The model incorporates constraints concerning the satisfaction of the ordered quantities, without exceeding standard tolerances, and so, overproduction is not allowed. Moreover, reels of lateral waste greater than a minimum width value $(2.1 \mathrm{~m})$ are sent to the Intermediate Stock for later usage.

The second LP model implemented, Model(2), takes advantage of the possibility of negotiating overproduction above standard tolerances with the client. However, production of reels to the Intermediate Stock is not permitted and, so, only patterns with width equal or greater than a minimum value $(2.1 \mathrm{~m})$ are considered. This characteristic can lead to problem infeasibility as all the patterns 
Table 7

Pattern enumeration

\begin{tabular}{|c|c|c|c|c|c|}
\hline \multirow[t]{2}{*}{$\begin{array}{l}\text { Production } \\
\text { order }\end{array}$} & \multicolumn{2}{|c|}{$\begin{array}{l}\text { No. ordered items } \\
\text { (\% width of master reel) }\end{array}$} & \multicolumn{2}{|c|}{$\begin{array}{l}\text { No. auxiliary } \\
\text { reels }\end{array}$} & \multirow[t]{2}{*}{$\begin{array}{l}\text { No. feasible } \\
\text { patterns }\end{array}$} \\
\hline & Reels & Sheets & Reels & Sheets & \\
\hline 68 & $1(100 \%)$ & $9(23.66 \%)$ & 1 & 43 & 1700 \\
\hline 69 & $5(29.43 \%)$ & $0(0 \%)$ & 72 & 0 & 230 \\
\hline 70 & $2(36.29 \%)$ & $4(29.43 \%)$ & 6 & 19 & 160 \\
\hline 71 & $2(36.29 \%)$ & $5(31.65 \%)$ & 6 & 9 & 82 \\
\hline 72 & $1(100 \%)$ & $2(30.44 \%)$ & 1 & 5 & 15 \\
\hline 73 & $0(0 \%)$ & $13(31.77 \%)$ & 0 & 48 & 374 \\
\hline 74 & $0(0 \%)$ & $2(26.01 \%)$ & 0 & 16 & 23 \\
\hline 75 & $5(34.19 \%)$ & $14(26.12 \%)$ & 29 & 103 & 5600 \\
\hline 76 & $1(45.97 \%)$ & $2(27.82 \%)$ & 2 & 5 & 22 \\
\hline 77 & $2(36.29 \%)$ & $10(25.99 \%)$ & 6 & 49 & 2063 \\
\hline 78 & $2(37.5 \%)$ & $4(29.56 \%)$ & 19 & 205 & 2009 \\
\hline 79 & $3(32.93 \%)$ & $4(25.45 \%)$ & 15 & 12 & 350 \\
\hline 80 & $2(40.72 \%)$ & $8(32.16 \%)$ & 5 & 57 & 381 \\
\hline 81 & $1(100 \%)$ & $1(29.83 \%)$ & 2 & 1 & 6 \\
\hline 82 & $7(32.09 \%)$ & $12(32.69 \%)$ & 108 & 55 & 2458 \\
\hline 83 & $9(25.62 \%)$ & $9(32.17 \%)$ & 817 & 35 & 16,060 \\
\hline 84 & $2(34.67 \%)$ & $4(30.04 \%)$ & 6 & 19 & 136 \\
\hline
\end{tabular}

containing a particular ordered item may be eliminated. Besides the length associated to each pattern, $x_{p}$, overproduction above ordered quantities of reels $(i)$ and sheets $(j)$ are also included as decision variables to minimize, $v_{i}$ and $v_{j}$ :

$$
\min Z=\sum_{p=1}^{n_{p}} x_{p}+\sum_{i=1}^{n_{i}} v_{i}+\sum_{j=1}^{n_{j}} v_{j} .
$$

In the example previously considered, the solution of both Model (1) and Model (2) are identical since the solution to Model (1) does not use patterns larger than $2.1 \mathrm{~m}$ and solution of Model (2) does not exceed the standard tolerances. This means that neither there is production to the Intermediate Stock nor there is the need of negotiating exceeding quantities with the client. The LP optimal solution obtained is presented in Table 8. The optimal objective function value is 69891.52.

\section{Rounding heuristic}

The rounding procedure is applied to the solution of both LP models and is intended to fulfill those constraints of integer nature previously ignored, such as:

(1) Fixed finished reels diameters imposed by the customer must be satisfied, meaning that the paper length of cutting patterns including such reels must always be multiple of the requested diameter. In order to minimize the impact of this heuristic procedure, the quantities ordered 
Table 8

Optimal solution (all the remaining decision variables/cutting patterns are 0)

\begin{tabular}{ll}
\hline $\begin{array}{l}\text { Decision variables } \\
\text { (cutting patterns) }\end{array}$ & Length (mm) \\
\hline$x_{10}($ FP 12) & 18744.37 \\
$x_{12}$ FP 16) & 548.05 \\
$x_{14}$ FP 21) & 29177.93 \\
$x_{19}$ FP 37) & 21421.17 \\
\hline
\end{tabular}

of reels of fixed diameter are adjusted to the closest multiple of the length of one reel before building the LP model.

(2) The minimum weight for combination of sheets constraint, equivalent to a minimum paper length, intends to avoid inefficient use of the cutters.

(3) Alike the previous item, the minimum weight for cutting pattern constraint is intended to prevent inefficient use of the winder, while establishing a minimum quantity of paper to cut with each cutting pattern used.

The rounding heuristic starts with the final solution of the LP model (non-zero length patterns) and tries to adjust those pattern lengths in order to satisfy the referred constraints. The new solution is kept as close as possible to the LP one and must satisfy the ordered quantities. First, the rounding procedure tries to eliminate those patterns which do not respect the minimum weight conditions (constraints 2 and 3 above). Precaution must be taken not to eliminate the unique pattern containing some ordered item. Then, the remaining patterns must be rounded up in order to compensate the effect of the destroyed ones. This rounding algorithm is presented in Fig. 5. This procedure consists basically in successively sorting the cutting patterns by the number of items not satisfied in each pattern, and augmenting the quantity to be cut with the first cutting pattern of the list until, at least, one unsatisfied item becomes satisfied. This procedure is repeated until all the items in all cutting patterns are satisfied.

This rounding procedure can lead to over-production above standard tolerances, even when Model(1) is used.

In the solution presented in Table 8, only the constraint concerning the minimum weight for combination of sheets is not being satisfied by the length of FP 16( $\left.x_{12}\right)$ since it is smaller than the minimum weight for combination of sheets determined for that pattern $(2730.00 \mathrm{~mm})$. As the only order in that pattern is PR 1002 and it also exists in FP $21\left(x_{14}\right)$, pattern FP 16 can be eliminated and the length of FP 21 must be adjusted to include the quantity of PR 1002 that was being cut from FP 16. The final solution is presented in Table 9.

Fig. 6 shows the output of COOL for the data in Table 2.

\section{Computationa Iresults}

The main purpose of the computational tests was to validate the solution procedure adopted and to establish a comparative analysis between the two linear programming models developed (Model(1) 


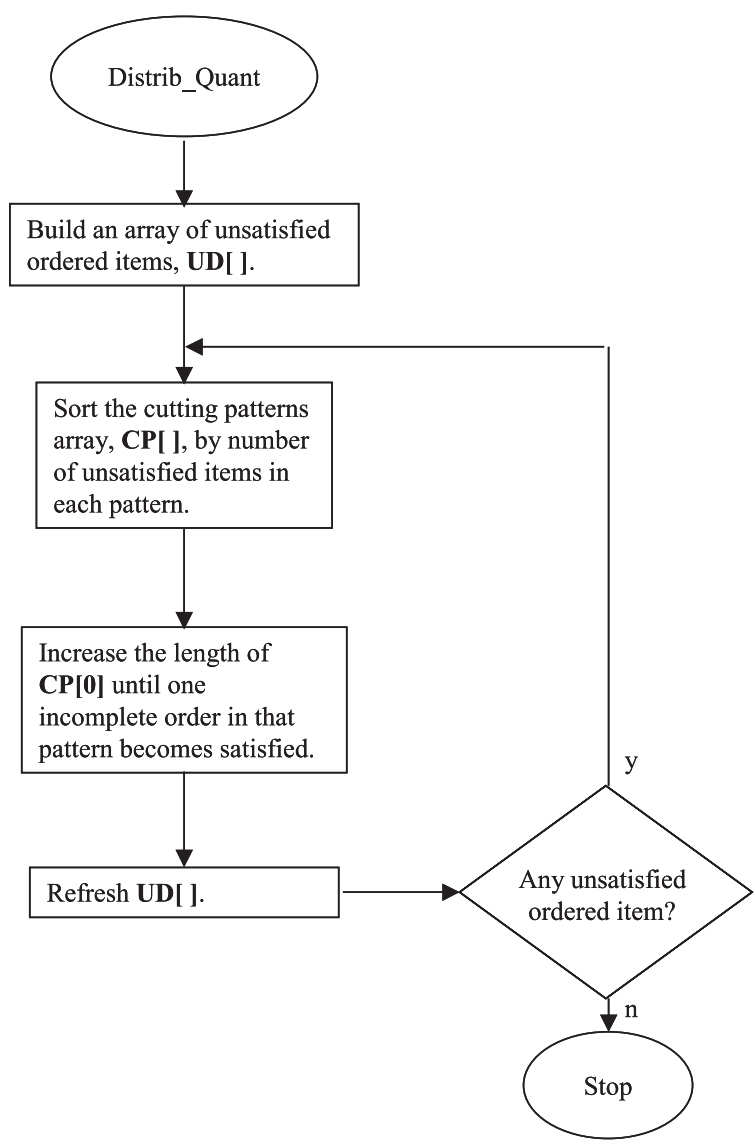

Fig. 5. Flowchart of the rounding procedure.

Table 9

Final solution (after the rounding procedure)

Decision variables

Length (mm)

(cutting patterns)

$x_{10}$ (FP 12)

$x_{14}$ (FP 21)

18744.37

$x_{19}$ (FP 37)

30000.00

21421.17

and Model(2)). The data used in this first set of computational runs was provided by the Marketing Department of the company and corresponds to real problems solved at the paper mill. The number of ordered items involved range from 3 to 16 and the maximum and minimum width of the ordered items are 1392 and $238 \mathrm{~mm}$, respectively, being the average width $690 \mathrm{~mm}$, approximately. These are relative small instances but, by doing this, the company intends to allow the system user to easily evaluate the performance of COOL in the initial phase of usage. 


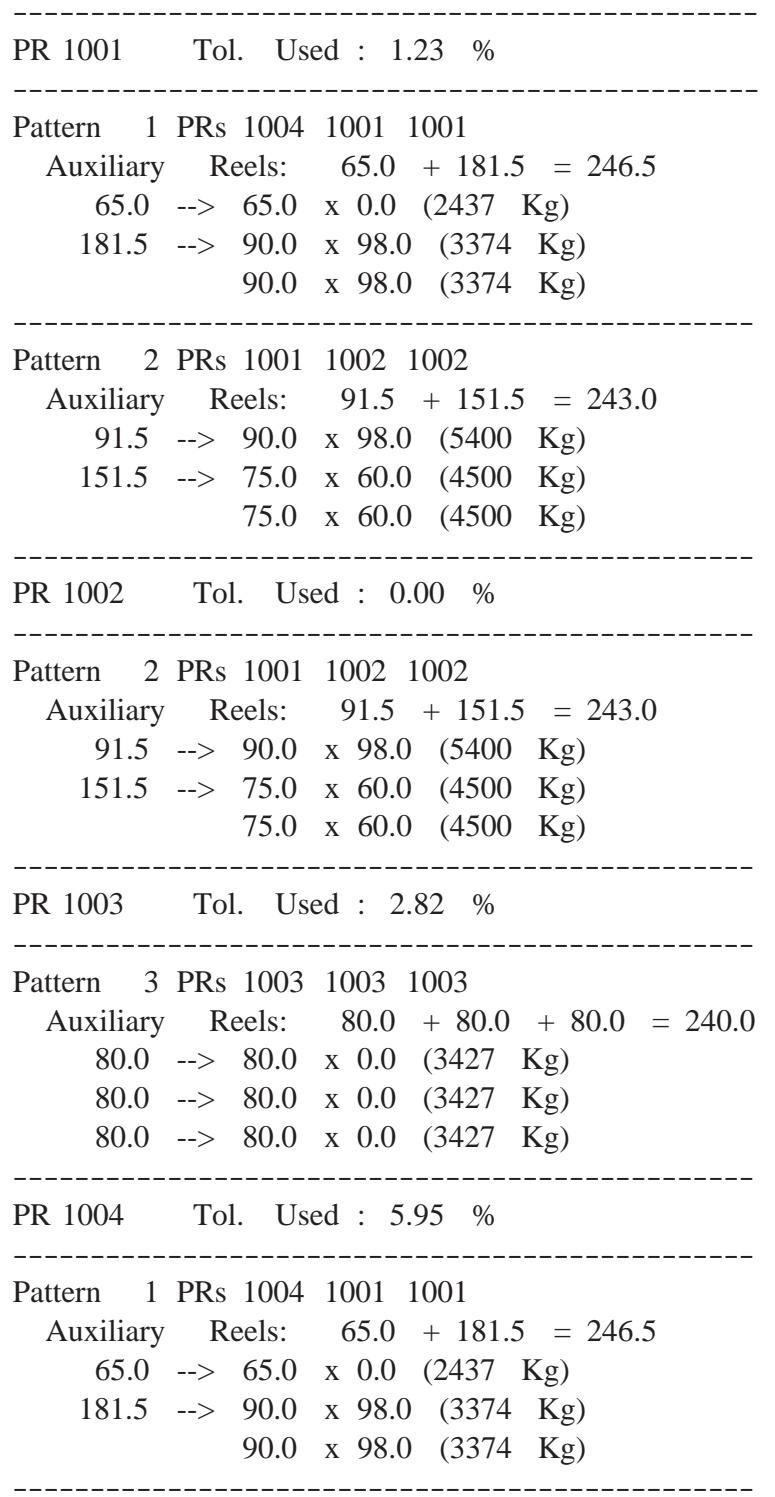

Fig. 6. Output of COOL.

Data used in the computational tests is available at www.apdio/sicup.

The algorithms were implemented using the $\mathrm{C}$ programming language. The computational results were obtained with a Pentium III at $450 \mathrm{MHz}$.

In order to evaluate the quality of the solutions obtained with the linear models and rounding heuristic described above, an IP model was implemented. This IP model minimizes the amount of paper produced while strictly satisfying the ordered quantities. In order to consider those integer 
constraints mentioned above, several integer variables are included:

- Minimum weight for combination of sheets (Min_Weight_CSheets):

$$
\begin{aligned}
& x_{p}=0 \vee x_{p} \geqslant \text { Min_Weight_CSheets }\left\{\begin{array}{l}
x_{p} \leqslant \delta_{p} M \\
x_{p} \geqslant \delta_{p} \text { Min_Weight_CSheets }
\end{array}\right. \\
& M \rightarrow \infty \\
& \delta_{p} \text { binary; }
\end{aligned}
$$

- Fixed finished reels diameters (Fixed_Diam):

$$
\begin{aligned}
& x_{p}=n_{p} \text { Fixed_Diam } \\
& n_{p} \text { integer; }
\end{aligned}
$$

- Minimum weight for cutting pattern (Min_Weight_CPatt):

$$
\begin{aligned}
& x_{p}=0 \vee x_{p} \geqslant \text { Min_Weight_CPatt }\left\{\begin{array}{l}
x_{p} \leqslant \gamma_{p} M \\
x_{p} \geqslant \gamma_{p} \text { Min_Weight_CPatt }
\end{array}\right. \\
& M \rightarrow \infty \\
& \gamma_{p} \text { binary; }
\end{aligned}
$$

The IP model was solved using the Mixed Integer Programming module of the optimization software CPLEX v.6.0.

In Fig. 7, the performance of each solution procedure developed (based on the two LP models, Model(1) and Model(2)) is evaluated in terms of objective function value. In Fig. 7(a), for each model, the ratio of the results obtained with the IP model and those obtained with the linear procedure followed by the rounding heuristic are depicted for each test instance: the value of 1.00 in the $y$ axis corresponds to the IP model solution. From this chart it can be observed that the results of the linear based procedure are, in most cases, coincident with those obtained with the IP model: Model(1) attains the same objective function values of IP in $70 \%$ of the test instances while only approximately $50 \%$ of the results obtained with $\operatorname{Model}(2)$ are coincident with the IP results. Though, with only one exception, the IP results are never exceeded in more than $22 \%$.

The chart in Fig. 7(b) intends to prove the adequacy of the linear approach adopted and, so, the ratio of the results before and after the rounding procedure is computed. The value of 1.00 in the $y$ axis corresponds to the LP model solution before the rounding procedure. In most cases, the results of the LP routine are coincident with the final results, which means that, in those cases, the constraints of integer nature considered in the rounding procedure do not change the linear programming result.

Both charts show that the results obtained with Model(1), which minimizes the paper length produced and does not allow over production above tolerances, are never worse than those obtained with Model(2), which does not produce to the Intermediate Stock. Moreover, these results suggest the need to improve the rounding procedure in case of Model(2).

Table 10 compares the results obtained with the two linear programming models in terms of the three exceeding components: quantity produced to the Intermediate Stock (QuantStock), overproduction above standard tolerances (QuantTolExc) and quantity of paper that cannot be re-used in any 

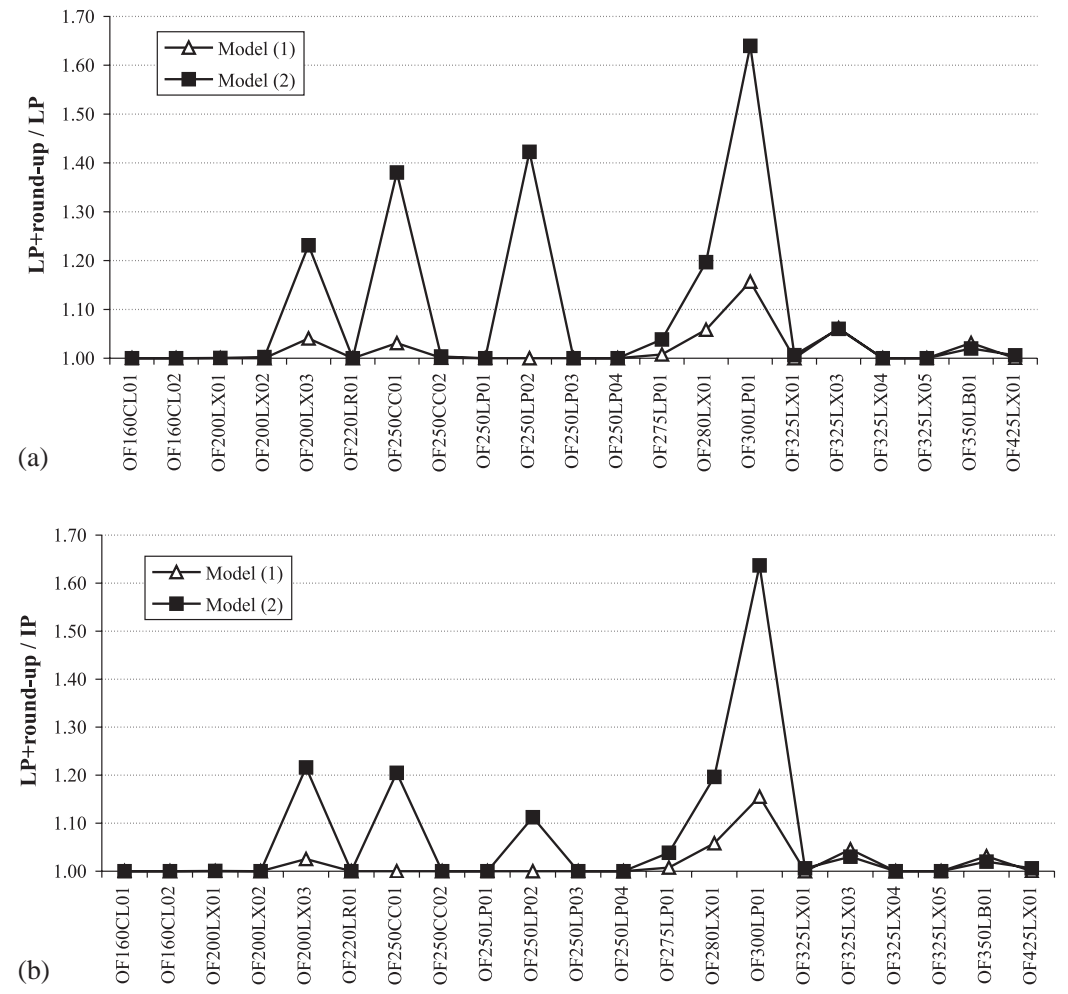

Fig. 7. Computational results.

way (Waste). All the values are expressed in terms of a percentage of the total weight of paper produced and reflect the objective function adopted in each model: $\operatorname{Model}(2)$ does not produce to the Intermediate Stock while Model(1) tries not to exceed standard tolerances. The amount in which, sometimes, these tolerances are exceeded in $\operatorname{Model}(1)$ are a consequence of the rounding procedure. However, they are quite small when compared to those obtained with $\operatorname{Model}(2)$.

Since waste is the only component which can not be re-used, Fig. 8 draws attention to the comparison between the values obtained with the two LP based procedures: final solutions based on Model(1) are seldom significantly worse than those attained with $\operatorname{Model}(2)$, in terms of paper waste minimization.

According to the comparative tests performed with this set of instances, Model(1) seems to perform better than Model(2) in all of them. Nevertheless, Model(2) was kept available in the final version of COOL, as each model may generate solutions more adequate to, or even required by, different industrial situations: when production to the Intermediate Stock is allowed or even recommended, Model(1) can be used; situations in which Intermediate Stock levels are high enough to forbid stock enlargement, Model(2) solutions may be required. In terms of efficiency, the LP approach lead to a reduction of the processing time of approximately $75 \%$ of the time used by the IP approach. Although the average resolution time of the IP approach for the instances tested was of $18 \mathrm{~s}$, situations may occur which would preclude the use of the IP approach in practice. 
Table 10

Computational results (LP (1) vs. LP (2))

\begin{tabular}{|c|c|c|c|c|c|c|}
\hline \multirow{2}{*}{$\begin{array}{l}\text { Production } \\
\text { order }\end{array}$} & \multicolumn{2}{|c|}{ QuantStock (\%) } & \multicolumn{2}{|c|}{ QuantTolExc (\%) } & \multicolumn{2}{|l|}{ Waste $(\%)$} \\
\hline & Model(1) & $\operatorname{Model}(2)$ & Model(1) & Model(2) & Model(1) & Model(2) \\
\hline OF160CL01 & 10.04 & 0.00 & 0.00 & 33.30 & 5.18 & 9.87 \\
\hline OF160CL02 & 10.04 & 0.00 & 0.00 & 33.30 & 5.18 & 9.87 \\
\hline OF200LX01 & 0.00 & 0.00 & 0.00 & 0.00 & 20.44 & 20.44 \\
\hline OF200LX02 & 0.00 & 0.00 & 0.00 & 0.00 & 3.94 & 3.94 \\
\hline OF200LX03 & 1.03 & 0.00 & 0.02 & 7.27 & 9.04 & 8.99 \\
\hline OF220LR01 & 0.00 & 0.00 & 0.00 & 0.00 & 3.41 & 3.41 \\
\hline OF $250 \mathrm{CC} 01$ & 0.00 & 0.00 & 0.00 & 0.00 & 18.65 & 18.65 \\
\hline OF $250 \mathrm{CC} 02$ & 0.00 & 0.00 & 0.00 & 0.00 & 18.35 & 18.35 \\
\hline OF250LP01 & 0.00 & 0.00 & 0.00 & 0.00 & 3.23 & 3.23 \\
\hline OF250LP02 & 10.06 & 0.00 & 0.04 & 30.93 & 3.65 & 6.12 \\
\hline OF250LP03 & 0.00 & 0.00 & 0.00 & 0.00 & 16.62 & 16.62 \\
\hline OF250LP04 & 0.00 & 0.00 & 0.00 & 0.00 & 3.23 & 3.23 \\
\hline OF275LP01 & 0.00 & 0.00 & 0.00 & 0.00 & 7.65 & 7.65 \\
\hline OF280LX01 & 0.00 & 0.00 & 0.01 & 0.19 & 3.95 & 3.96 \\
\hline OF300LP01 & 0.00 & 0.00 & 0.12 & 11.46 & 3.28 & 3.39 \\
\hline OF325LX01 & 7.05 & 0.00 & 0.00 & 10.94 & 20.40 & 25.88 \\
\hline OF325LX03 & 12.86 & 0.00 & 0.04 & 31.04 & 5.19 & 16.42 \\
\hline OF325LX04 & 0.00 & 0.00 & 0.00 & 0.00 & 6.11 & 6.11 \\
\hline OF325LX05 & 0.00 & 0.00 & 0.00 & 0.00 & 6.11 & 6.11 \\
\hline OF350LB01 & 3.59 & 0.00 & 0.01 & 17.02 & 17.86 & 18.08 \\
\hline OF425LX01 & 5.20 & 0.00 & 0.00 & 13.06 & 5.05 & 4.67 \\
\hline
\end{tabular}

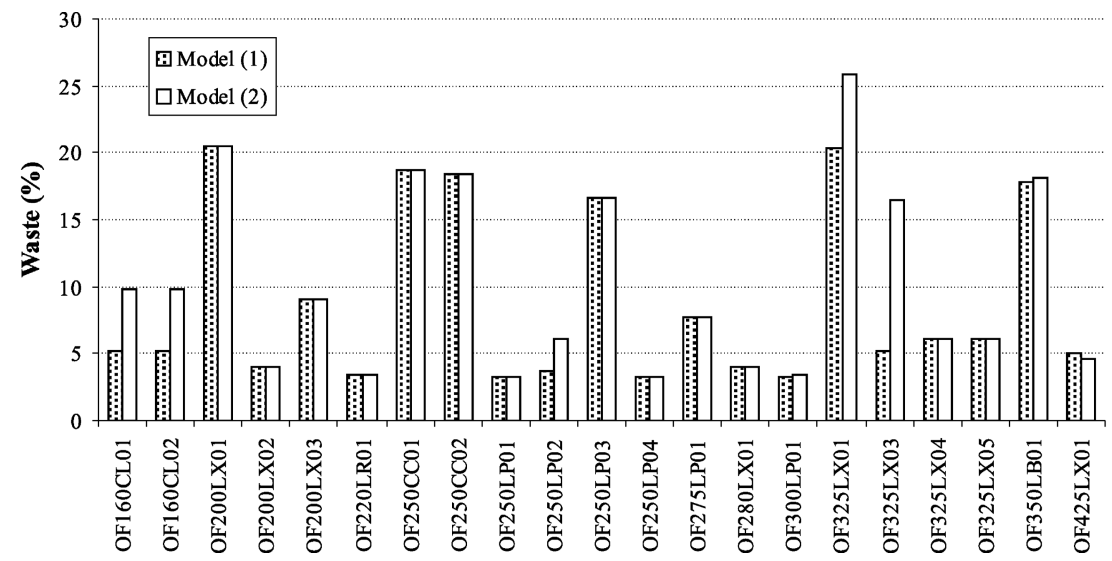

Fig. 8. Waste (\%) obtained with LP Model(1) and Model(2). 


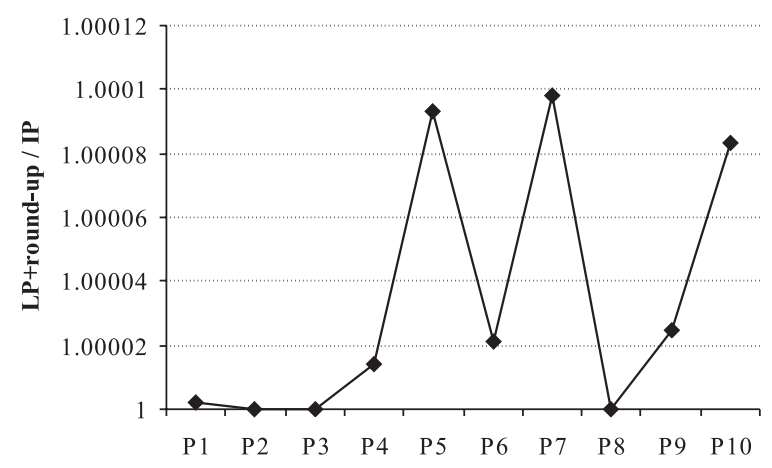

Fig. 9. Computational results for large-scale instances.

Table 11

Computational time for large-scale instances

\begin{tabular}{|c|c|c|c|c|c|c|}
\hline & \multirow[b]{2}{*}{$\begin{array}{l}\text { Pattern } \\
\text { generation (s) }\end{array}$} & \multicolumn{3}{|c|}{ Integer programming } & \multicolumn{2}{|c|}{$\begin{array}{l}\text { Linear programming } \\
+ \text { rounding procedure }\end{array}$} \\
\hline & & $\begin{array}{l}\text { Optimization } \\
\text { (s) }\end{array}$ & $\begin{array}{l}\text { Total } \\
\text { time }(\mathrm{s})\end{array}$ & $\begin{array}{l}\text { Nr. } \\
\text { Nodes }\end{array}$ & $\begin{array}{l}\text { Optimization } \\
\text { (s) }\end{array}$ & $\begin{array}{l}\text { Total } \\
\text { time }(\mathrm{s})\end{array}$ \\
\hline $\mathrm{P} 1$ & 232 & 32 & 264 & 36 & 17 & 249 \\
\hline $\mathrm{P} 2$ & 128 & 131 & 259 & 12 & 11 & 139 \\
\hline P3 & 885 & 21 & 906 & 0 & 17 & 902 \\
\hline P4 & 260 & 162 & 422 & 21 & 9 & 269 \\
\hline P5 & 562 & 2908 & 3470 & 2465 & 15 & 577 \\
\hline P6 & 112 & 108 & 220 & 75 & 9 & 121 \\
\hline P7 & 228 & 2592 & 2820 & 1996 & 13 & 241 \\
\hline P8 & 401 & 13 & 414 & 0 & 13 & 414 \\
\hline P9 & 61 & 604 & 665 & 1193 & 7 & 68 \\
\hline $\mathrm{P} 10$ & 204 & 2499 & 2703 & 6487 & 11 & 215 \\
\hline
\end{tabular}

A set of larger instances was generated and tested in order to evaluate the performance in terms of efficiency of the developed LP-based approach when a larger number of ordered items is considered. All of these instances include 30 items of various dimensions and were generated by randomly choosing among the items of the real instances considered above. The main purpose of these tests was to evaluate the efficiency of our approach under extreme conditions.

These tests were performed using Model(1) and the resulting ratio $L P+$ round-up/IP is depicted in Fig. 9. As can be observed, the solutions obtained with both our approach and the IP approach based on Cplex do not significantly differ in terms of objective function. The computational time used by both approaches to solve the 10 instances tested is listed in Table 11. As it would be expected, the optimization time is almost always larger in integer programming. Although the magnitude of this difference does not usually restrain the use of integer programming, some cases occur (P5, P7 and $\mathrm{P} 10$ ) in which this difference may be significant in terms of operational efficiency. 
COOL has been validated by the paper mill and is currently in use. Considerable benefits, both in economic and environmental terms, are proclaimed. The transformation losses were reported as having decreased at least 3\%, which corresponds to more than 1000 tons of paper a year! Also, considerable savings have been achieved in terms of energy and additives, which, unlike paper, cannot be recycled.

\section{Conclusions}

This paper describes the system COOL, developed to deal with a particular cutting-stock problem occurring in a Portuguese paper mill. The minimization of trim loss when producing and cutting master reels of paper is the main goal of the solution procedure developed. For technological reasons, the master reels of paper have to be cut in two phases, while satisfying a numerous set of technological and operational constraints. This two-phase cutting characteristic was of crucial importance for the solution procedure adopted.

Due to the combinatorial nature of this problem, a solution method based on the enumeration of the cutting patterns has been devised. These patterns are selected, in order to satisfy most of the imposed constraints, and used as columns in a linear programming formulation of the problem which is intended to determine the approximated amount/weight of paper to produce of each pattern. Some constraints of integer nature, previously ignored, are included in a post-optimization procedure through which the linear programming solution is submitted.

Two linear programming based models were developed and tested. The results attained with these two models are quite satisfactory, but a comparative analysis between them, and between each one and those obtained with an integer programming model suggests the need of improving the rounding procedure. However, the alternative of developing a global heuristic to solve the problem should not be discarded.

It is shown that the automated planning of paper cutting has important advantages for industrial purposes: the production cycle can be reduced and the inclusion of last minute orders can be done, allowing better customer service. The system COOL is already being used at the paper mill and the feedback has been quite enthusiastic, as considerable economical, operational and environmental benefits have been achieved.

\section{References}

[1] Haessler RW. A heuristic programming solution to a nonlinear cutting stock problem. Management Science 1971;17(12):B793-802.

[2] Johnson MP, Rennick C, Zak E. Skiving addition to the cutting stock problem in the paper industry. SIAM Review 1997;39(3):472-83.

[3] Johnston RE. OR in the paper industry. OMEGA The International Journal of Management Science 1981;9(1): 43-50.

[4] Dowsland KA, Dowsland WB. Packing problems. European Journal of Operational Research 1992;56:2-14.

[5] Golden BL. Approaches to the cutting stock problem. AIIE Transactions 1976;8(2):265-74.

[6] Hinxman A. The trim loss and assortment problems: a survey. European Journal of Operational Research 1980;5: $8-18$.

[7] Carvalho JVd, Rodrigues AG. An LP-based approach to a two-stage cutting stock problem. European Journal of Operational Research 1995;84:580-9. 
[8] Ferreira JS, Neves MA, Fonseca e Castro P. A two-phase roll cutting problem. European Journal of Operational Research 1990;44:185-96.

[9] Haessler RW. Solving the two-stage cutting stock problem. OMEGA The International Journal of Management Science 1979;7(2):145-51.

[10] Oliveira JF, Ferreira JS. A faster variant of the gilmore and gomory technique for cutting stock problems. JORBEL 1994;34(1):23-38.

Maria Helena Correia is Teaching Assistant at Faculdade de Economia e Gestão, Universidade Católica Portuguesa, at Porto, and a Researcher in the Manufacturing Systems Engineering Unit at INESC-Porto. She received her MSc degree from the Faculdade de Engenharia da Universidade do Porto. She is now a PhD student at the same University. Her research interests are in Cutting and Packing Problems and Combinatorial Optimization. She has published articles in journals such as ITOR, Pesquisa Operacional and Investigação Operacional.

José Fernando Oliveira is Auxiliary Professor at the Department of Electrical and Computers Engineering of the Faculdade de Engenharia da Universidade do Porto and Senior Researcher in the Manufacturing Systems Engineering Unit at INESC-Porto, in Portugal. He received his PhD by the Faculdade de Engenharia da Universidade do Porto, in 1995. His primary areas of interest are Combinatorial Optimization and Cutting and Packing Problems. He is the chairman of the international group "SICUP_-The Special Interest Group on Cutting and Packing", which gathers practitioners, researchers and Operations Research educators with interests in the area of Cutting and Packing (www.apdio.pt/sicup). $\mathrm{He}$ is also Vice-President of "APDIO-The Portuguese Operations Research Society" and Managing Editor of the journal "Investigação Operacional". He has been the scientific leader of several R\& D projects, funded either by governmental agencies or industrial companies and he has published articles in several international journals such as EJOR, JORBEL, ORSpektrum, Pesquisa Operacional, ITOR and Investigação Operacional.

José António Soeiro Ferreira is Associate Professor, with Chair Aggregation, at the Faculdade de Engenharia da Universidade do Porto, Leader of the area of Decision and Optimization at the Instituto de Engenharia de Sistemas e Computadores do Porto and President of APDIO - the Portuguese Operational Research Society. Doctor Ferreira received his $\mathrm{PhD}$ in Operational Research from the Technical University of Denmark and his primary areas of R\& D are problem analysis and structuring methods, decision support, simulation and optimization methods. He has published articles in journals such as EJOR, Int.J. Prod. Res., Engineering Optimization, Control and Cybernetics, ITOR, JORBEL, Pesquisa Operacional and Investigação Operacional. 